\title{
Impact of Road Humps on the Pavement Surface Condition
}

\author{
Mohamed Hamed Zakaria ${ }^{a^{*}}$, Amal Al-Ayaat ${ }^{\mathrm{b}}$, Sayed Shwaly ${ }^{\mathrm{c}}$ \\ ${ }^{a}$ Assistant Lecturer, Civil Engineering Dept., Faculty of Engineering, Kafr El-Sheikh University, Egypt. \\ ${ }^{b}$ Lecturer, Civil Engineering Dept., Faculty of Engineering, Kafr El-Sheikh University, Egypt. \\ ${ }^{c}$ Associate Professor, Public Works Dept., Faculty of Engineering, Mansoura University, Egypt.
}

Received 01 March 2019; Accepted 07 June 2019

\begin{abstract}
In order to fight against over-speeding, the government and people in Egypt resorted to the installation of speed humps without adequate studies. On this basis, speed humps became widespread in most of the Egyptian roads in a semi-random way. It has been observed that the pavement condition of the roads has deteriorated in the vicinity of these humps. For impact assessment of speed humps on the pavement condition index (PCI), three roads link Kafr El-Sheikh city with three major towns in Kafr El-Sheikh governorate were selected to conduct PCI survey. The results indicated that the presence of speed humps contributes greatly to reduce the pavement condition index (PCI) values. It should be mentioned that the average reduction in PCI values ranged between $15 \%$ and $22 \%$ due to the presence of speed humps. Also, the most frequently observed distress on the pavement sections including humps considered for the selected roads was Raveling and Rutting. Accordingly, to avoid the pavement defects at the locations where the speed humps are installed, it is proposed to study the structural section of the road in the vicinity of the speed hump to resist the braking force and speed reduction effect.
\end{abstract}

Keywords: Speed Humps; Pavement Condition Index; PCI.

\section{Introduction}

Nevertheless, there has been an increased use of speed humps that were placed without getting proper permits and did not meet the design specifications [1]. Additionally, these speed humps are sometimes constructed in a manner that may cut the storm water drainage path causing surface water ponding over the pavement surface [2]. These improper speed humps affect the pavement condition and may be a factor in reducing the pavement service life [2]. Thus it became necessary to study the pavement condition of the sections of the road in the vicinity of the speed humps so that possible the pavement defects can be avoided

According to the above, the main aim of the research was to study the impact of speed hump on the pavement condition index (PCI) for the studied road sections. In order to evaluate the impact of speed hump on the pavement condition index (PCI), three roads were chosen to carry out the PCI survey. These roads link the city of Kafr El-Sheikh with three surrounding major towns within Kafr El-Sheikh Governorate region. These roads represent different area types, different average daily traffic (ADT) and various truck percentages. The resulted PCI values for these road sections were calculated and compared with each other in order to evaluate the direct effect of speed hump presence.

\footnotetext{
* Corresponding author: mohammed_hamed@eng.kfs.edu.eg

http://dx.doi.org/10.28991/cej-2019-03091334

(C) 2019 by the authors. Licensee C.E.J, Tehran, Iran. This article is an open access article distributed under the terms and conditions of the Creative Commons Attribution (CC-BY) license (http://creativecommons.org/licenses/by/4.0/).
} 


\section{Literature Review}

Speed humps and employed as means of calming traffic and reduce speeds of vehicles [3]. Several parameters are utilized to give a full description of a speed hump. These parameters include geometric and layout design parameters. The geometric parameters include hump length, hump height, hump profile, and hump width [4]. Layout parameters include spacing between speed hump, construction materials, marking, and signage. Many researchers have studied the potential positive and negative effects of calming devices, especially speed humps [1-7]. It is worth mentioning that very little work has been done to study the impact speed humps on the pavement condition [8].

Bekheet (2014) carried out a study to investigate the possible effects off illegal speed traffic humps of pavement condition in Alexandria city, Egypt [2]. The results proved that the presence of such improper speed humps could reduce the average pavement condition index (PCI) of the examined road sections by up to 19 PCI points [2]. The research study involved 72 pavement sections from 24 projects on rural and urban roads distributed over all administrative districts of Alexandria Governorate. Data considered in the analysis included visual distress survey after 4 years of construction and quality control records from the time of construction. The analysis of the pavement condition of these sections was carried-out both at the network level and at the project level [2].

The most frequently observed distress on the pavement sections in the vicinity of speed hump locations considered in the research study was raveling, which is a functional distress, while the load-related distresses such as alligator cracking and rutting were observed in less than $10 \%$ of the sections studies. As a result, it could be deduced that the standard pavement structure used by RTD is structurally adequate for the average traffic levels [2].

Another study was conducted in Upper Egypt showed that the pavement conditions are greatly influenced by the presence of speed humps and hump characteristics [8]. The study was to assess the impact of speed hump characteristics on pavement condition using data from 52 humps located in intercity two-lane, two-way road that connects two cities, Tahta and Gerga, in Sohag, Upper Egypt. Regression analysis was used to produce the best relationship between each PCI and speed hump characteristics. Several models were developed and presented. The results proved that the pavement conditions are greatly influenced by the presence of speed humps and hump characteristics. Regression analysis was used to produce the best relationship between each PCI and speed hump characteristics.

It shall be mentioned that previous studies have not been studied the PCI value out of the influence area of the speed hump, in order to compare the difference between the values in different areas. Also, it is recommended to study PCI over other roads in Egypt with different average daily traffic (ADT) volumes, speed hump characteristics, pavement structural capacity, traffic composition, pavement age, construction quality, etc. [8]. After all, it sounds that very little work has been done in Egypt to study the effect of speed humps on pavement condition.

\section{Study Area and Data Collection Methodology}

Figure 1 provides a summary of the research methodology utilized in this study.

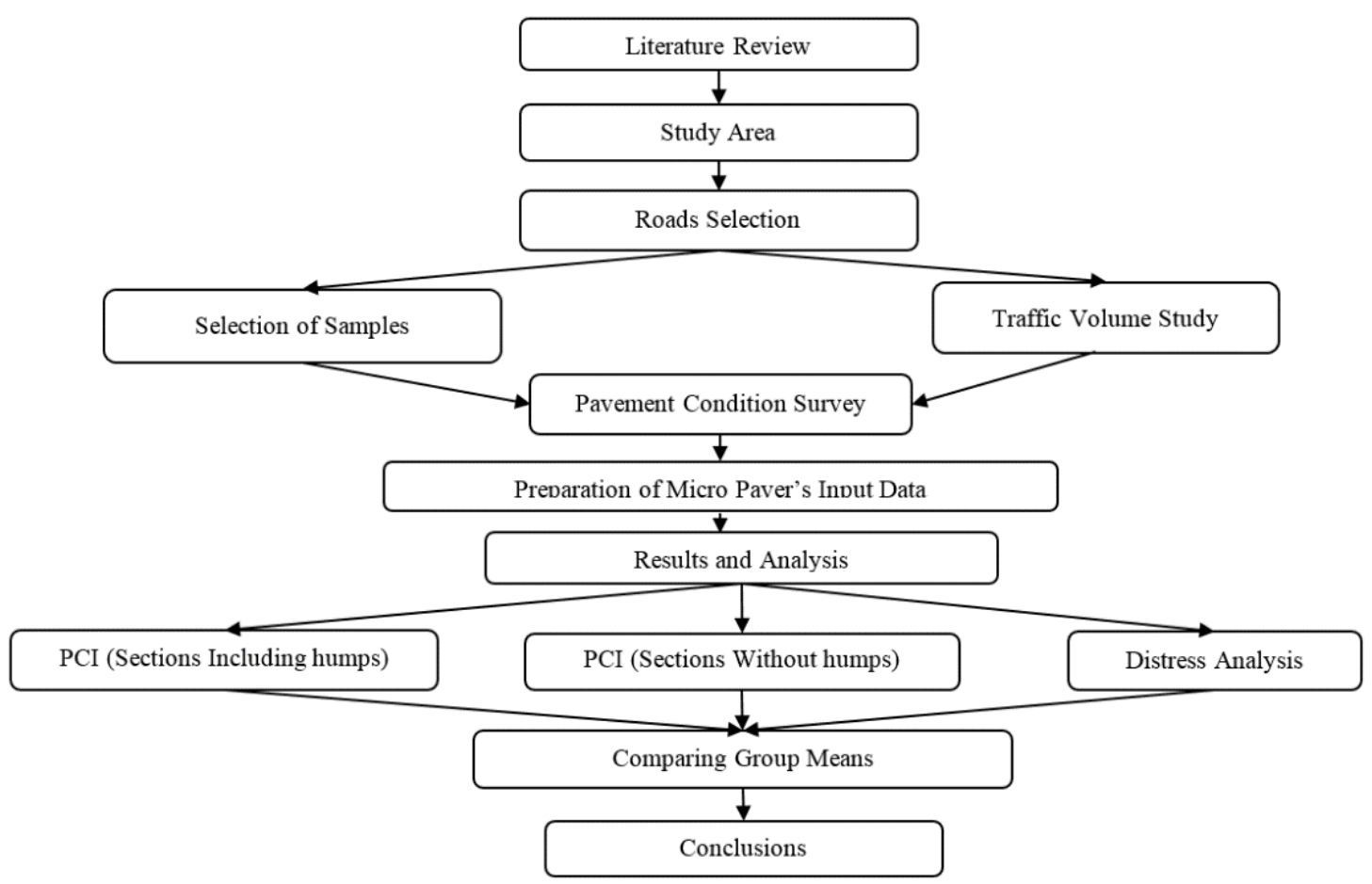

Figure 1. A summary of the research methodology 


\subsection{Roads Selection}

Three roads link the city of Kafr El-Sheikh with three major cities within the scope of Kafr El-Sheikh Governorate were chosen to survey for PCI calculations. Figure 2 shows the location of Kafr El-Sheikh Governorate in Egypt.

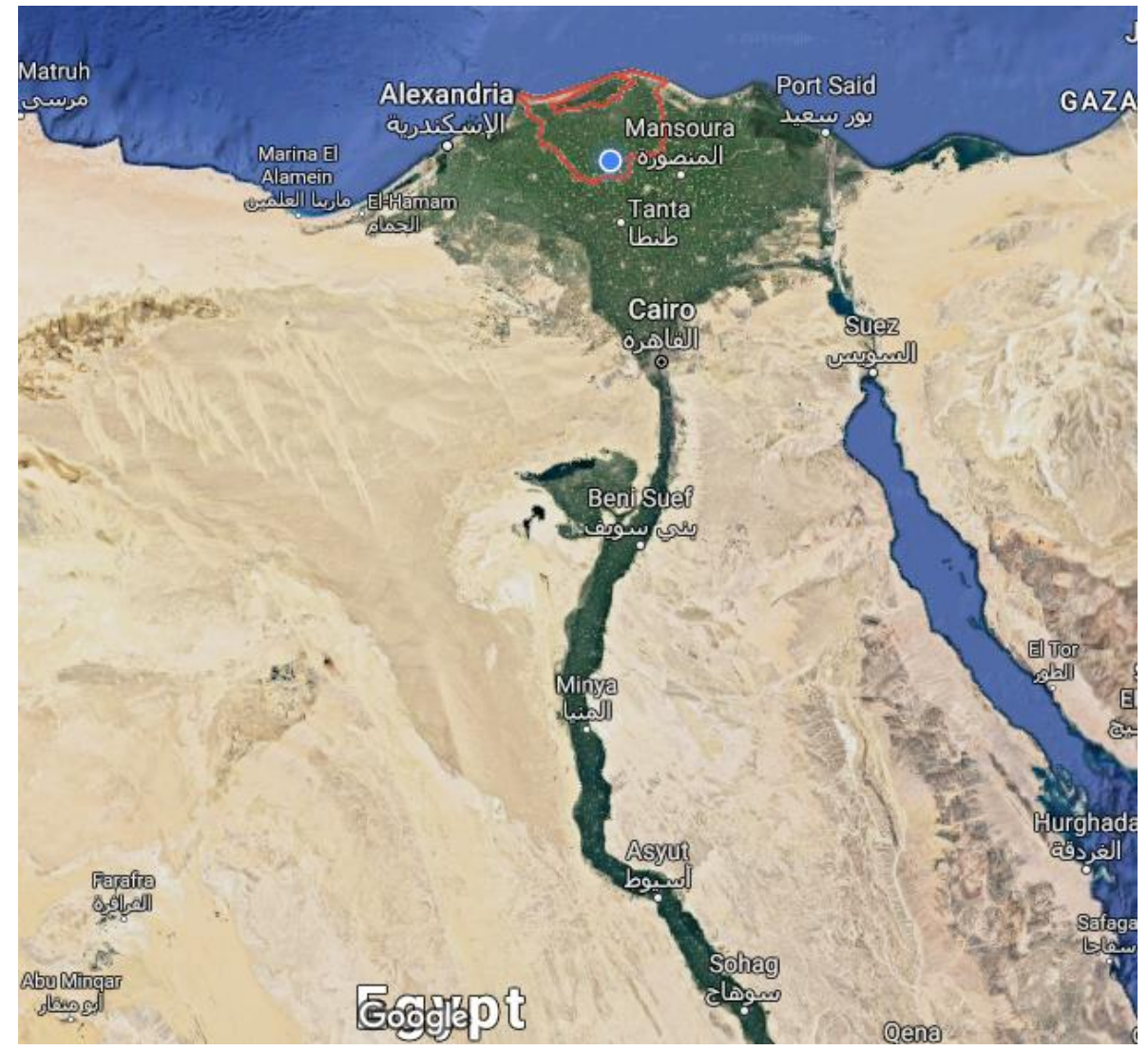

Figure 2. The Location of Kafr El-Sheikh Governorate in Egypt

These roads represent different kinds (divided and undivided), different population (highly and lowly populated area) and different traffic volumes. The information of these roads present in Table 1.

Table 1. Details of Selected Roads

\begin{tabular}{ccccccc}
\hline Case No. & Road Name & Section Length $(\mathbf{K m})$ & Width $(\mathbf{m})$ & Type & No. of lanes & Geometric Type \\
\hline 1 & Kafr El-Sheikh -Biyala & 24 (section) & 7 & Undivided & 2 & rural \\
2 & Kafr El- Sheikh - Sidi Salem & 24 & 7.75 & Undivided & 2 & rural \\
3 & Kafr El-Sheikh -Baltim & 20 (section) & $7.5 /$ Direction & Divided & 4 & rural \\
\hline
\end{tabular}

\subsection{Traffic Volume}

Traffic is one of the most significant factors that affect pavement condition. Detailed traffic counts were not available for the sections considered in the analysis. The count period should avoid special event or compromising weather conditions [9]. Count periods may range from 5 minutes to 1 year. Typical count periods are 15 minutes or 2 hours for peak periods, 4 hours for morning and afternoon peaks, 6 hours for the morning, midday, and afternoon peaks, and 12 hours for daytime periods [10]. Sunday and Thursday were selected for traffic counts because Sunday marks the start of the week and Thursday marks the end of the week, so these two days are expected to be more congested in terms of traffic. Typical peak periods are morning (8:00 am - 10:00 am) and evening (3:00 pm - 5:00 pm). Daily traffic volume is calculated based on peak hour volume (PHV). Finally, based on the limited traffic counts and knowledge of land use neighboring the roads under consideration, traffic will be estimated and categorized into different levels for each pavement section based on Average Daily Traffic (ADT) and Percentage of Truck (\% Trucks).

\subsection{Road Samples Selection}

The following steps are needed for PCI calculations $[11,12]$ : 
1. Determine the total number of the sample units in the pavement section $(\mathrm{N})$ by dividing the section length by the sample unit length which is $(100 \mathrm{~m})$,

2. Determine the minimum number of sample units (n) that must be surveyed to obtain an adequate estimate of the section's PCI. Equation (1) was used to obtain (n).

$$
n=\frac{N s^{2}}{\left(e^{2} / 4\right)(N-1)+s^{2}}
$$

Where:

$n=$ The minimum number of sample units that must be surveyed;

$N=$ Total number of sample units in the pavement section;

$e=$ Allowable error in the estimate of the section PCI ( $e$ was equal to 5); and

$s=$ Standard deviation of the PCI between sample units in the section (s =10 was used; initially inspected).

1. Determine the sampling interval (i) by dividing the total number of the sample unit $(\mathrm{N})$ by the minimum number of the sample units (n). Equation 2 was used to obtain (n).

$$
i=\frac{N}{n}
$$

Where:

$N=$ Total number of sample units in the pavement section

$n=$ The minimum number of sample units that must be surveyed

Based on the above, the number of samples to be examined was determined to evaluate the pavement condition index for the pre-determined sections.

Table 2 shows the required number of samples to be tested for each section.

Table 2. Details of Required Samples Size

\begin{tabular}{ccccc}
\hline Road Name & Section Length $(\mathbf{K m})$ & Total Samples (N) & Required Samples (n) & Sampling interval (i) \\
\hline Kafr El-Sheikh - Biyala & 24 (section) & 240 & 15 & 16 \\
Kafr El-Sheikh - Sidi Salem & 24 & 240 & 15 & 16 \\
Kafr El-Sheikh - Baltim & 20 (section) & 200 & 15 & 13 \\
\hline
\end{tabular}

\subsection{Selection of Samples Including Speed Humps}

To study the impact of the speed humps on the pavement condition of the road, a number of samples are selected from the location that have speed humps. Taking into consideration the following:

1. The distribution of samples along the road is random so that it includes the beginning, middle and end of the road

2. The number of samples with speed hump shall not be less than the number of samples to be inspected from the road

\subsection{Pavement Condition Survey}

A manual survey was performed on the selected roads. Each road was divided into sample units. The type and severity of sample distress was assessed by visual inspection of the pavement sample units and the quantity of each distress was measured. Typically, this procedure requires a team of at least two engineers [12]. For example, Figure 3 shows the beginning and the end coordinates of the road under study using the GPS as well as the locations of the selected samples to evaluate the pavement condition of the road. 


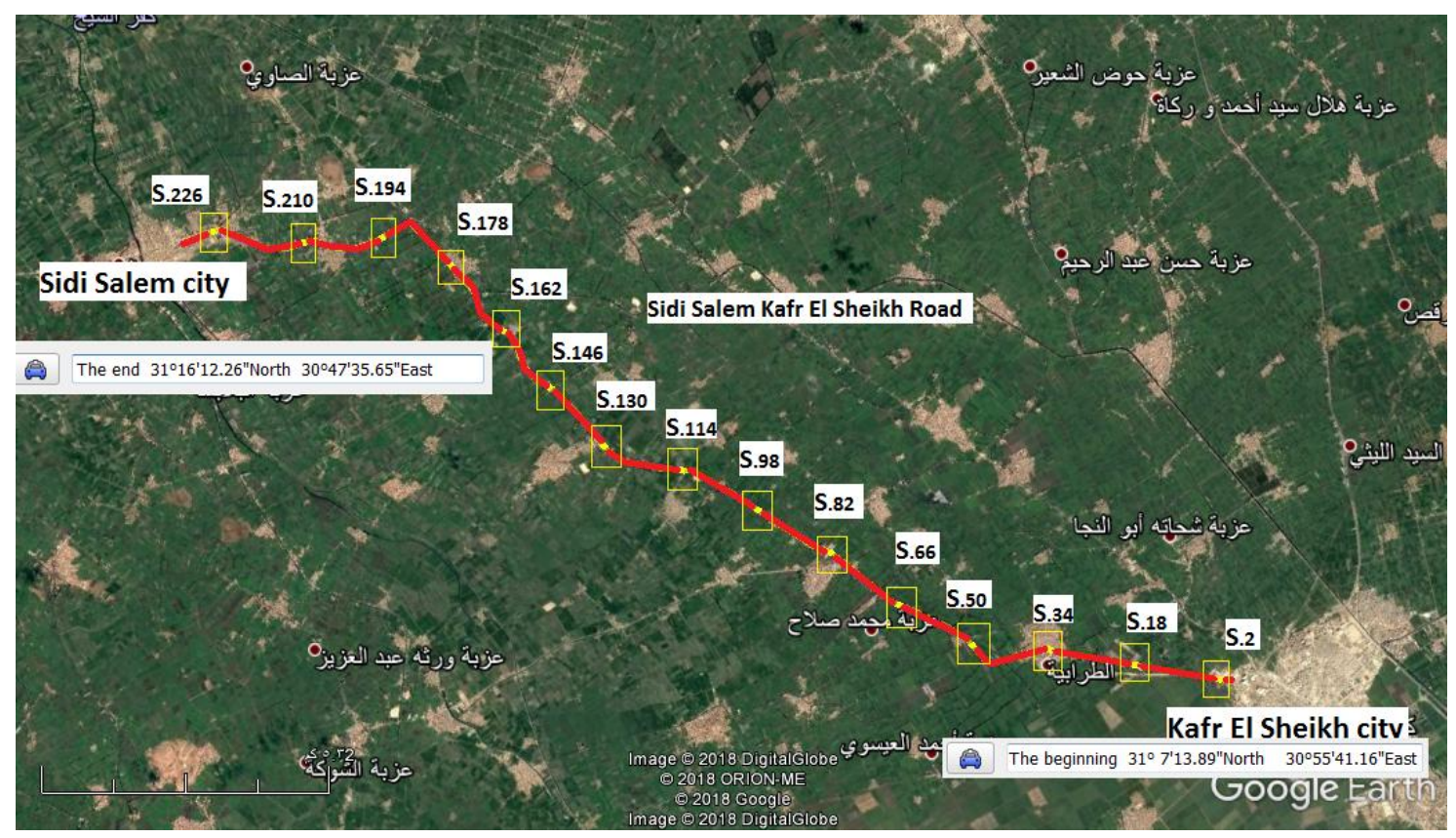

Figure 3. The Locations of the Selected Samples of Sidi Salem-Kafr El-Sheikh Road Using the GPS (Google maps)

\subsection{Preparation of Micro Paver's Input Data}

After recording the inspection data into the sheets, surface distresses evaluation was calculated based on a numerical rating from 0 to 100, pavement condition index (PCI), as mentioned in Figure 4. The calculation was performed using Micro PAVER software $[13,14]$. The PAVER system classifies pavement network to branches and sections prior to perform condition analysis.

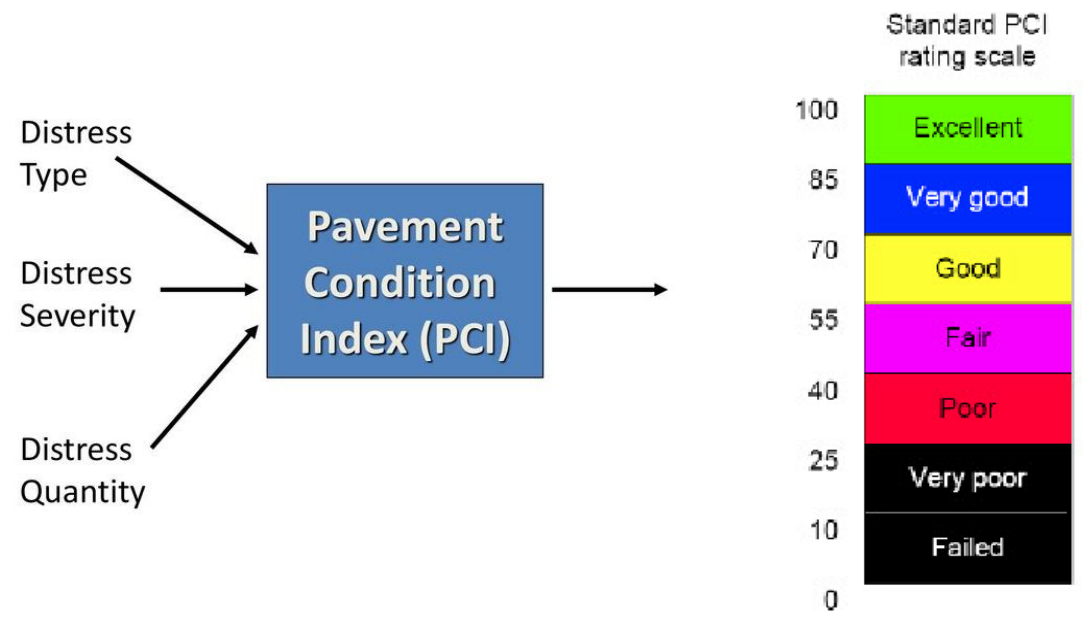

Figure 4. PCI Procedure [15]

\section{Results and Analysis}

Three roads for inspection were chosen: Kafr El-Sheikh- Sidi Salem road, Kafr El-Sheikh-Baltim road, and Kafr ElSheikh-Biala road. During the inspection task for each sample, the inspector measured each distress type and severity, and recorded these data on an asphalt-surfaced pavement inspection sheet. After recording the inspection data into the sheets, surface distresses evaluation was calculated based on a numerical rating from 0 to 100 , pavement condition index (PCI), as mentioned above. The calculation was performed using Micro PAVER software [3].

\subsection{Traffic Volume}

Limited traffic counts were available for the roads considered in the analysis. Figure 5 shows example of the flow rate for each vehicle class at afternoon peak on Kafr El-Sheikh- Biala road. Also, Figure 5 shows that microbuses represent more than $28 \%$ of the traffic volume, followed by passenger cars, which represent more than $26 \%$ of the traffic volume at afternoon peak periods. The figure also shows the percentage of heavy vehicles. A summary of the traffic measurements conducted on each road is given in Table 3. 


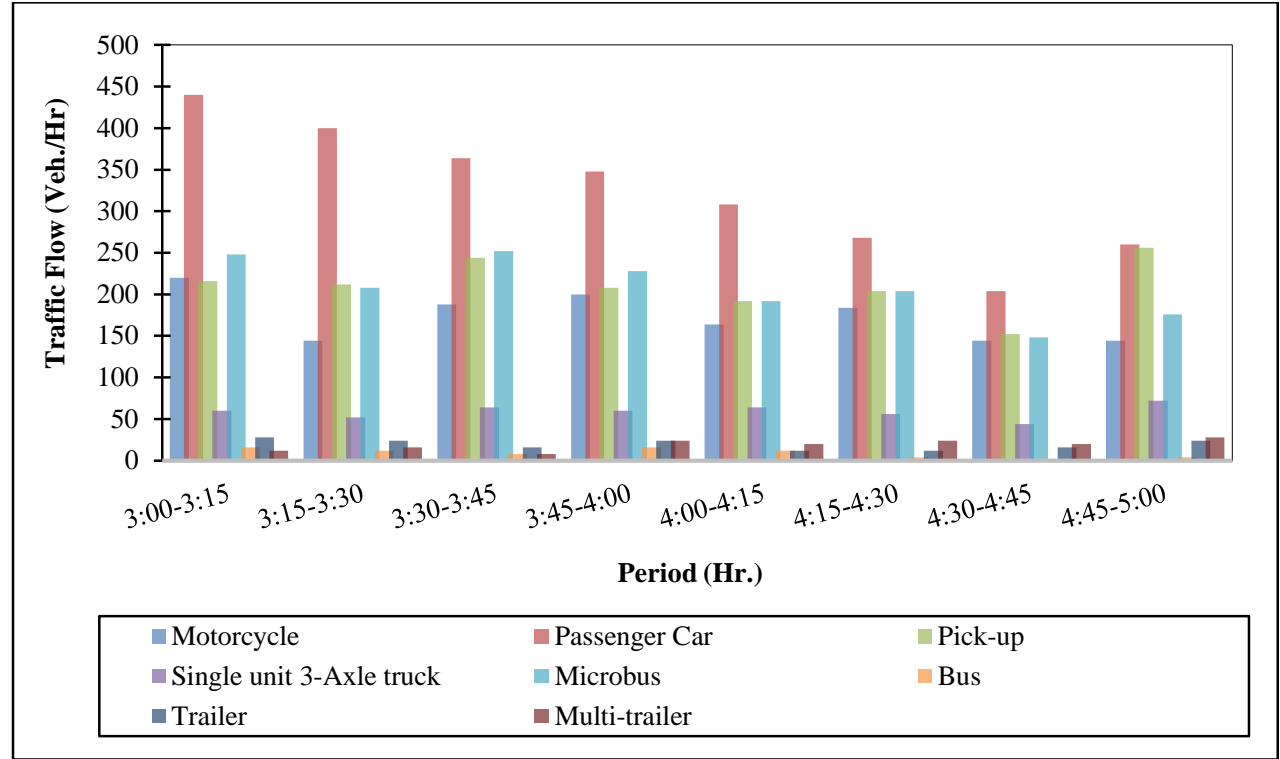

Figure 5. Vehicle Classification on Kafr El-Sheikh- Biala Road at (3:00-5:00) pm

Table 3. Results of Traffic Volumes Study

\begin{tabular}{cccc}
\hline Road Name & Kafr El-Sheikh - Sidi Salem & Kafr El-Sheikh - Biyala & Kafr El-Sheikh - Baltim \\
\hline Peak hour traffic volume, (veh/hr) am & 1521 & 1390 & 1554 \\
Peak hour traffic volume, (veh/hr) pm & 1430 & 1440 & 1650 \\
K-factor & 0.15 & 0.15 & 0.15 \\
Daily Traffic (veh./day) & 10140 & 9600 & $11000 /$ direction \\
\hline
\end{tabular}

Table 4 illustrates the percentage of each transport mode proportioned to the total vehicles observed during peak periods on each studied road. It can be seen that the percentage of heavy vehicles varies from one road to another.

Table 4. Percentage of the Different Transport Modes for Each Studied Section

\begin{tabular}{cccc}
\hline Road Name & Kafr El-Sheikh - Sidi Salem & Kafr El-Sheikh - Biyala & Kafr El-Sheikh - Baltim \\
\hline Motorcycle & $6.15 \%$ & $7 \%$ & $4 \%$ \\
Passenger Car & $21.9 \%$ & $26.75 \%$ & $19.2 \%$ \\
Pick-up & $21 \%$ & $21 \%$ & $22 \%$ \\
Single unit 3-Axle truck & $8 \%$ & $7.1 \%$ & $8.2 \%$ \\
Microbus & $35.3 \%$ & $28.75 \%$ & $35 \%$ \\
Bus & $0.9 \%$ & $1.5 \%$ & $0.2 \%$ \\
Trailer & $3.15 \%$ & $4 \%$ & $5.2 \%$ \\
Multi-trailer & $3.6 \%$ & $3.9 \%$ & $6.2 \%$ \\
\hline
\end{tabular}

\subsection{Evaluation of Pavement Condition}

The analysis is carried out at three levels. The first level is an assessment of the road condition with neglecting the sections that have speed humps in accordance with the criteria described above. The second level is an assessment of the pavement condition of the road based on the sections with speed humps only. The third level is to determine the effect of the presence of speed humps. This effect can be determined by comparing the average condition of the PCI values of sections with speed humps to the average condition PCI values of the sections with no speed humps for the same road.

\subsubsection{Pavement Condition Based on Samples without Speed Humps}

Figures 6 to 8 show the values of PCI along Kafr El Sheikh- Sidi Salem road, Kafr El-Sheikh- Biala road, and Kafr El-Sheikh- Baltim road, respectively. Also, the figures illustrated the locations of sections that have speed humps and how they are distributed along the road. It is also noted from the figures that the value of PCI is reduced in the case of sections with speed humps from other section. 


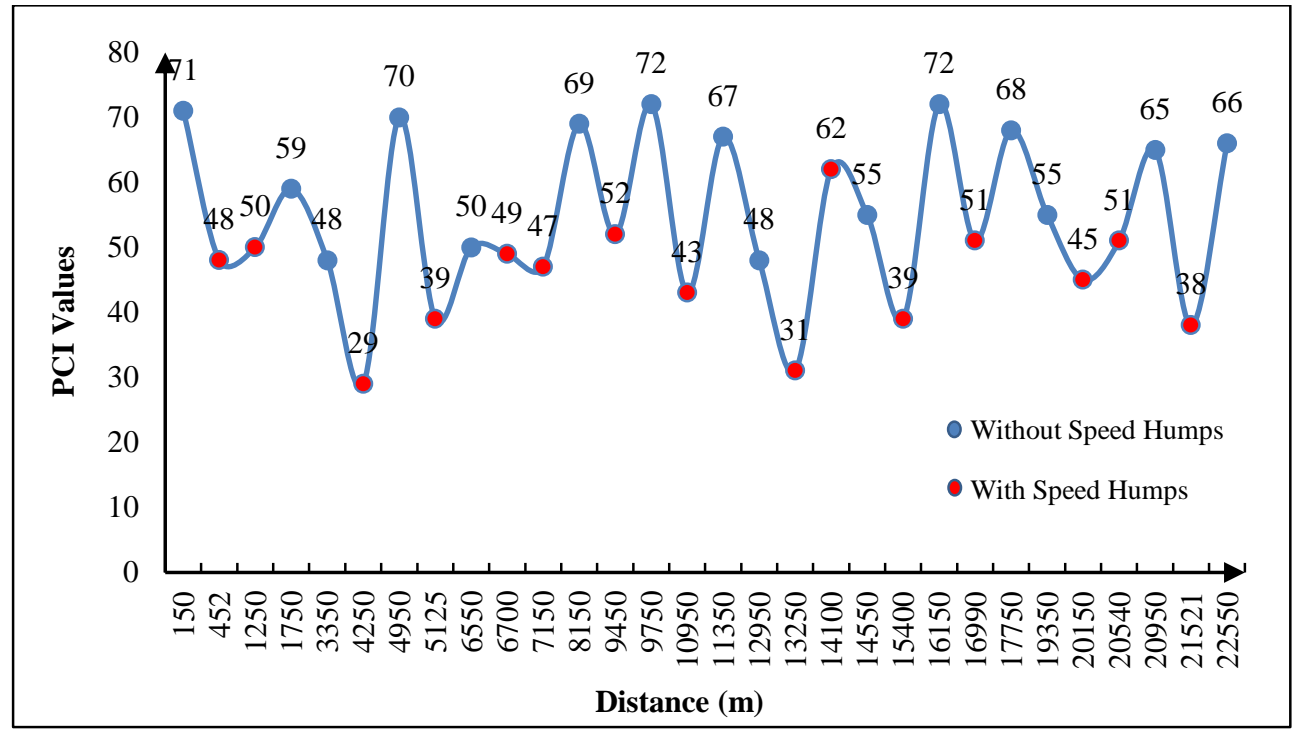

Figure 6. The Values of PCI along Kafr El-Sheikh- Sidi Salem Road

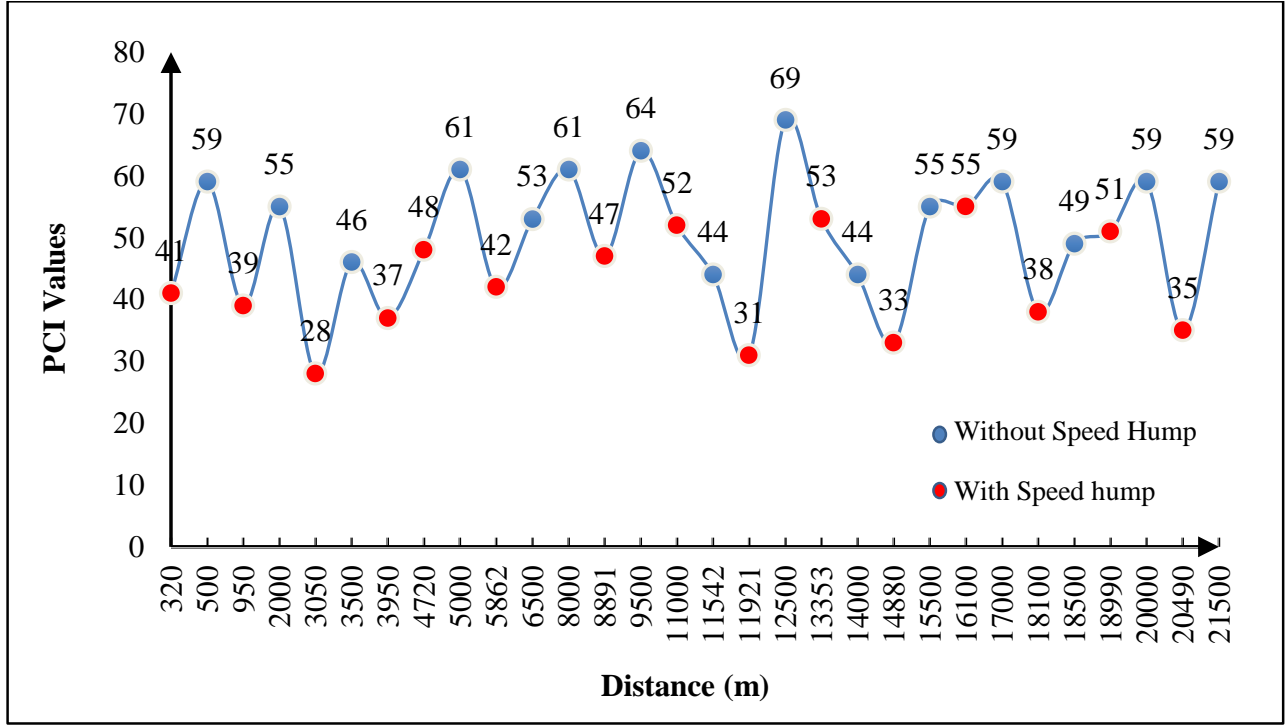

Figure 7. The Values of PCI along Kafr El-Sheikh- Biala Road

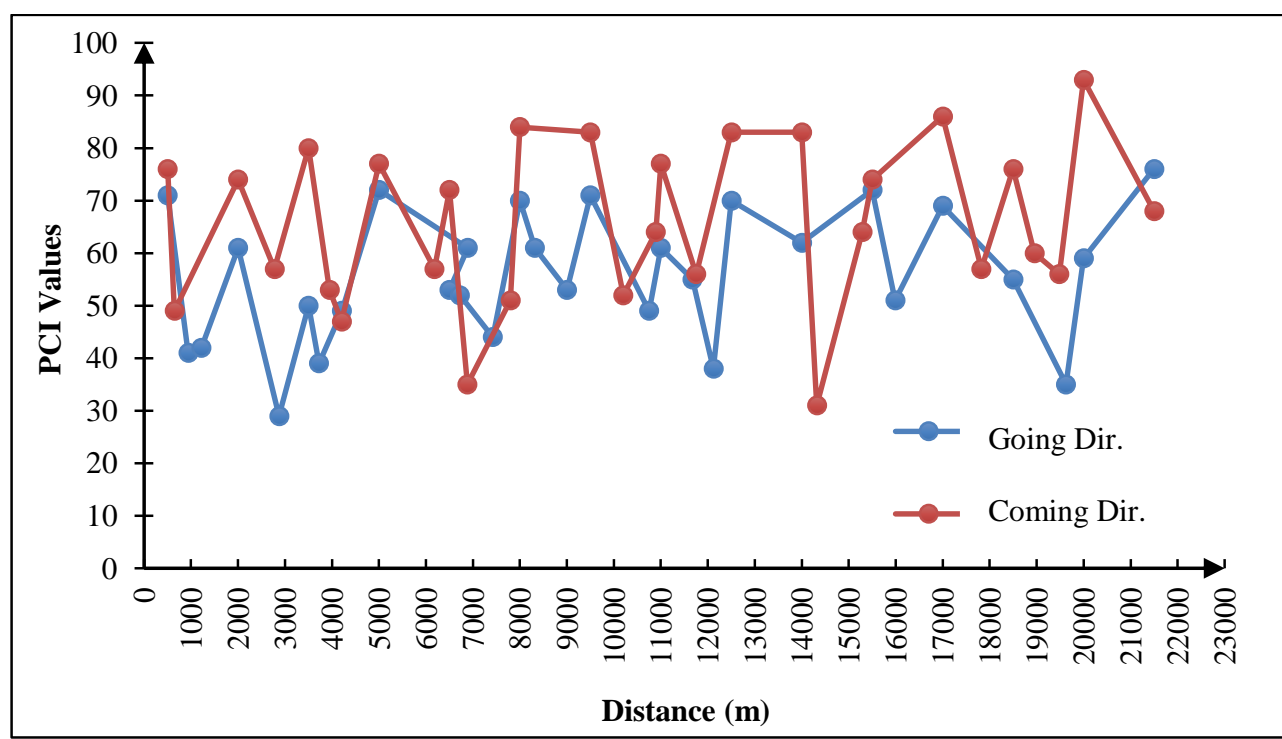

Figure 8. The Values of PCI along Kafr El-Sheikh- Baltim Road 


\subsubsection{Distress Analysis for Samples without Speed Humps}

The pavement distresses of the selected samples are analyzed to investigate the more frequently observed distresses as following:

\section{a. Kafr El-Sheikh- Sidi Salem Road}

Figure 9 shows the pavement distresses against deducted points percentage on Kafr El-Sheikh- Sidi Salem road, regardless of the severity level. The figure also shows that the load-related distresses were frequently observed, where Alligator Cracking was the most widely observed distress and contributed more than $30 \%$ of the total deducted points before the correction, while Rutting was observed in $9 \%$ of the sections. This observation indicates that the standard pavement structure used in the RTD in general may be structurally inappropriate for average traffic levels. On the other hand, some distresses, such as Reflective Cracking, and Slippage Cracking were not observed on any section.

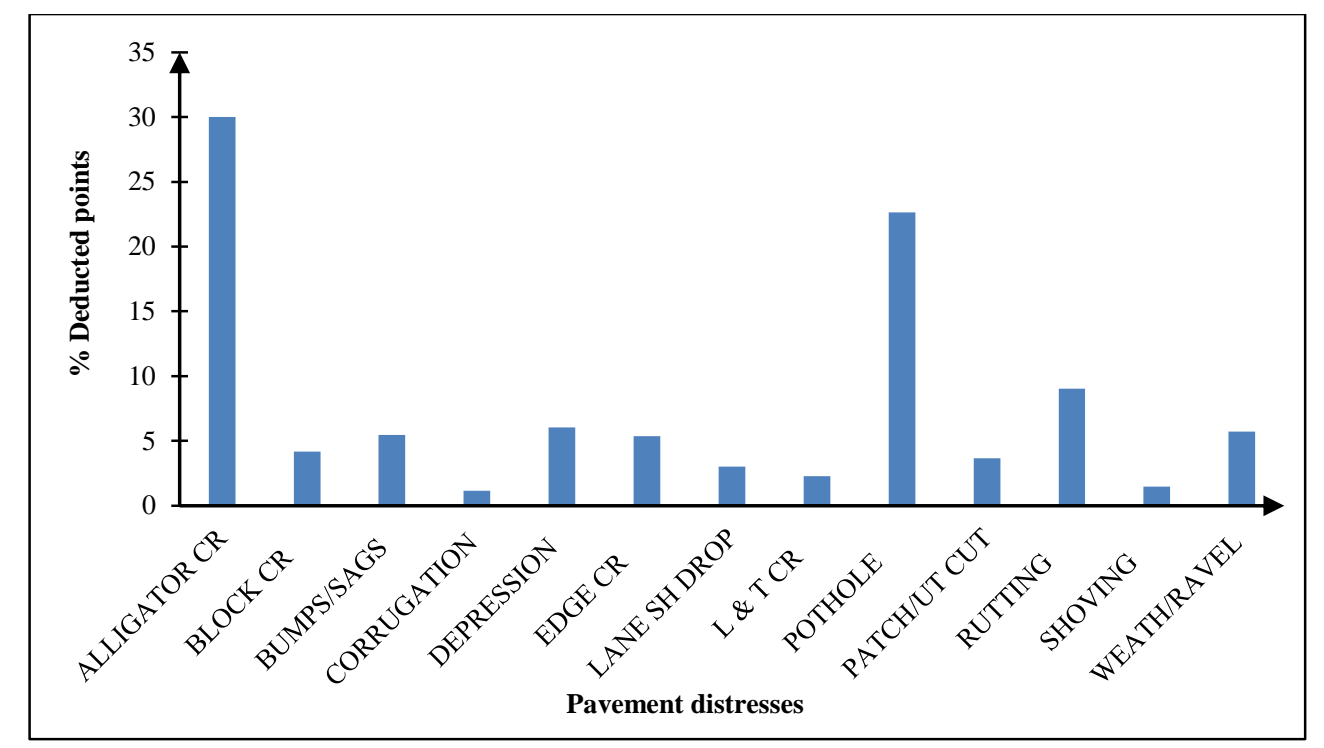

Figure 9. The Pavement Distresses against Ducted Points Percentage of the Selected Samples on Kafr El-Sheikh- Sidi Salem Road

\section{b. Kafr El-Sheikh- Biala Road}

Figure 10 shows the pavement distresses against deducted points percentage on Kafr El-Sheikh- Biala road. The figure also shows that the load-related distresses were frequently observed, where Alligator Cracking was the most widely observed distress and contributed more than $20 \%$ of the total deducted points before the correction, while Rutting was observed in $12 \%$ of the sections. Also, Raveling is functional distress, which was contributed $12.5 \%$ of the total deducted points before the correction.

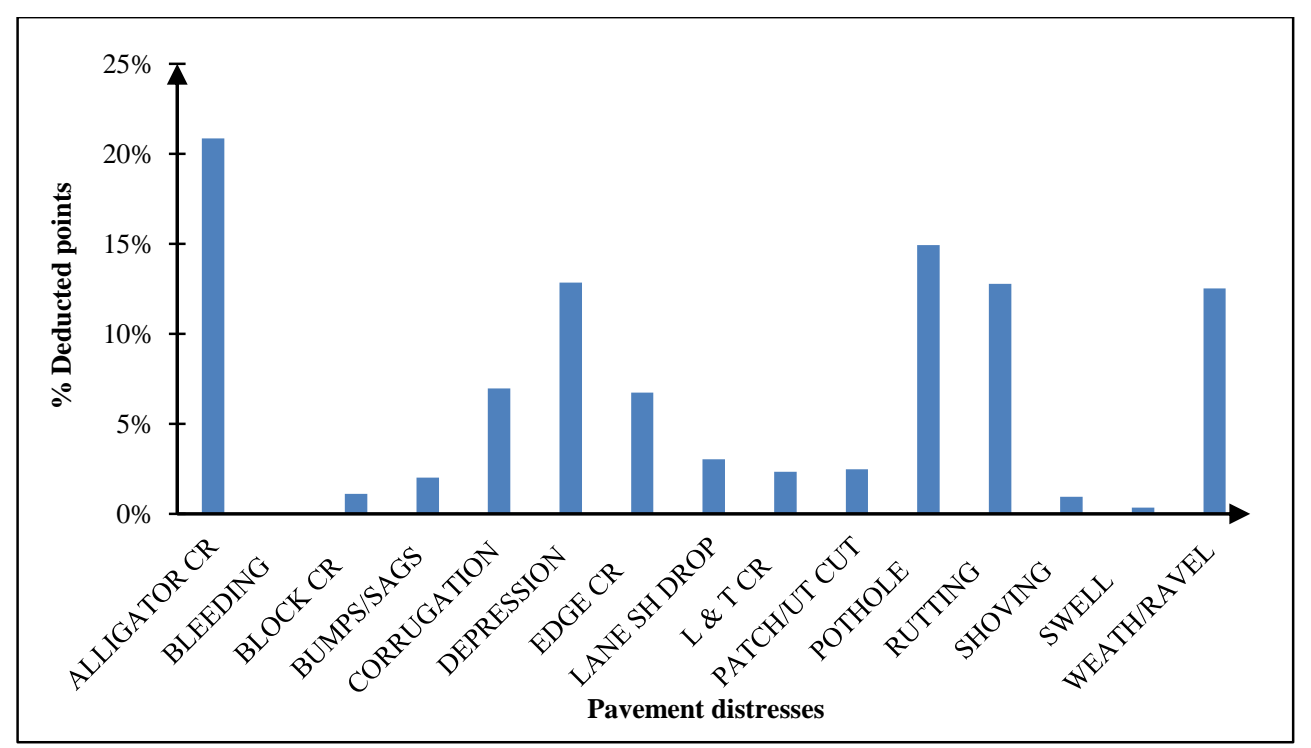

Figure 10. The Pavement Distresses against Deducted Points Percentage of the Selected Samples on Kafr El-Sheikh- Biala Road 


\section{c. Kafr El-Sheikh- Baltim Road}

Figure 11 shows the pavement distresses against deducted points percentage on Kafr El-Sheikh- Baltim road. The figure also shows that the load-related distresses were frequently observed, where Alligator Cracking was the most widely observed distress and contributed more than $15 \%$ of the total deducted points before the correction, while Block Cracking was contributed $12 \%$ of all samples. Also, Raveling is functional distress, which was contributed $16 \%$ of the total deducted points before the correction.

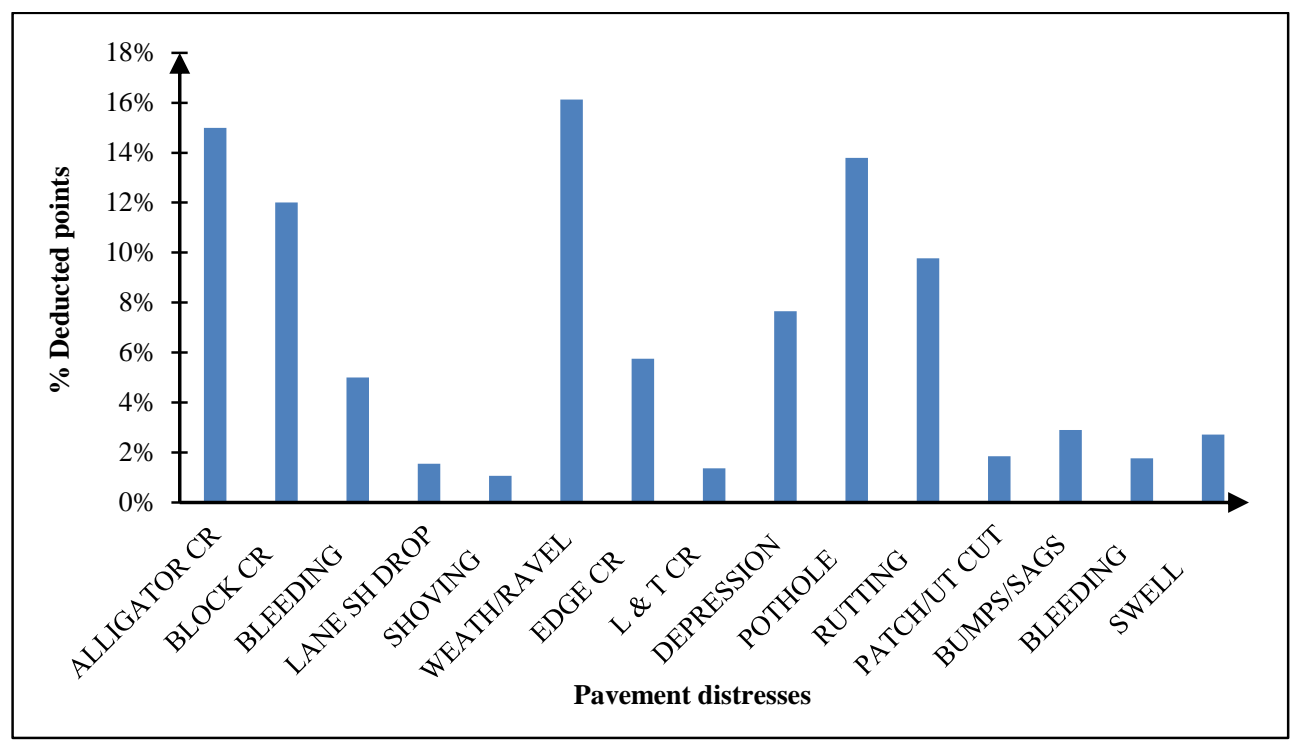

Figure 11. The pavement distresses against Deducted points percentage of the selected samples on Kafr El-Sheikh- Baltim road

\subsubsection{Distress Analysis for Samples with Speed Humps}

\section{a. Kafr El-Sheikh- Sidi Salem Road}

Figure 12 shows the pavement distresses against deducted points percentage for all samples with humps on Kafr ElSheikh- Sidi Salem road. The figure also shows that the most widely observed distress is Rutting, which was contributed $31 \%$ of the total deducted points before the correction. Where the Rutting is considered as load-related distresses. Also, Raveling is functional distress, which was contributed $26 \%$ of the total deducted points before the correction. On the other hand, some distresses, such as Reflective Cracking, Bleeding, and Slippage Cracking were not observed in any section.

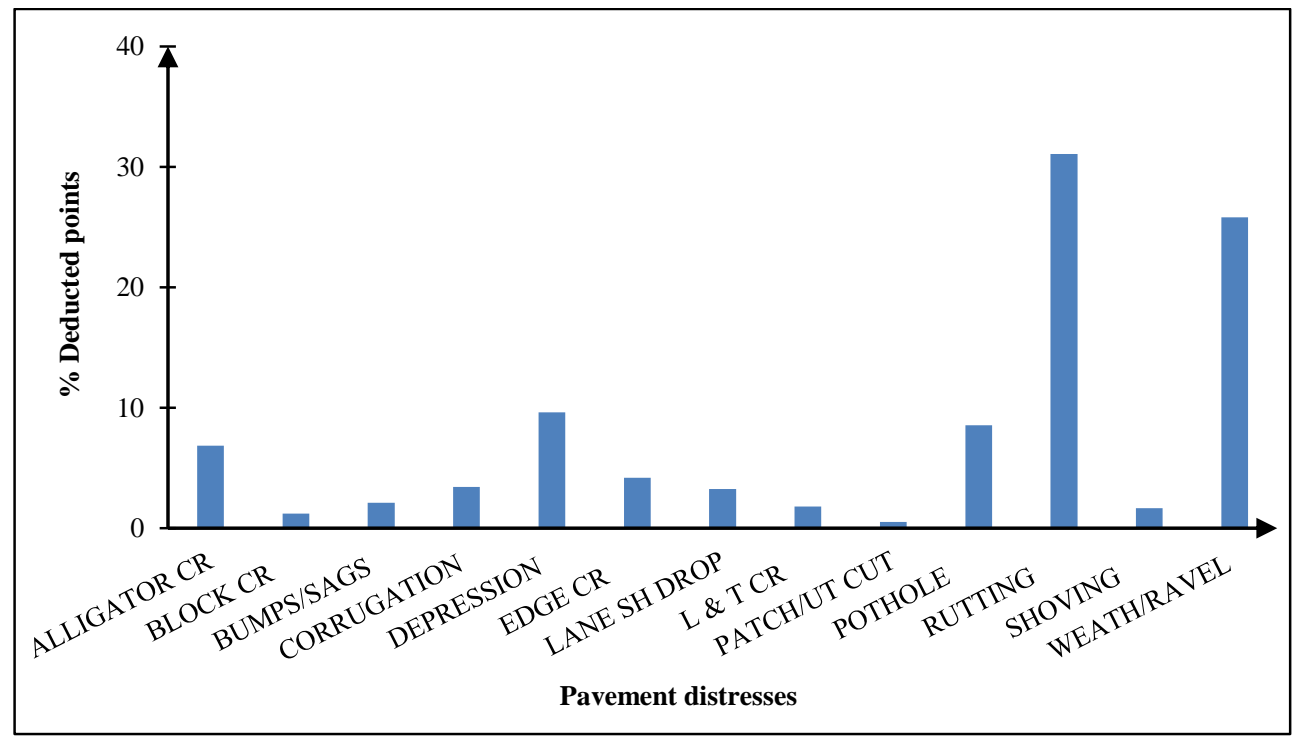

Figure 12. The Pavement Distresses against Ducted Points Percentage of the Sections with Speed Humps on Kafr El-SheikhSidi Salem Road 


\section{b. Kafr El-Sheikh- Biala Road}

Figure 13 shows the pavement distresses against deducted points percentage for all samples with humps on Kafr ElSheikh- Biala road. The figure also shows that the most widely observed distress is Rutting, which was contributed $22.7 \%$ of the total deducted points before the correction. Also, Raveling is functional distress, which was contributed $19.7 \%$ of the total deducted points before the correction.

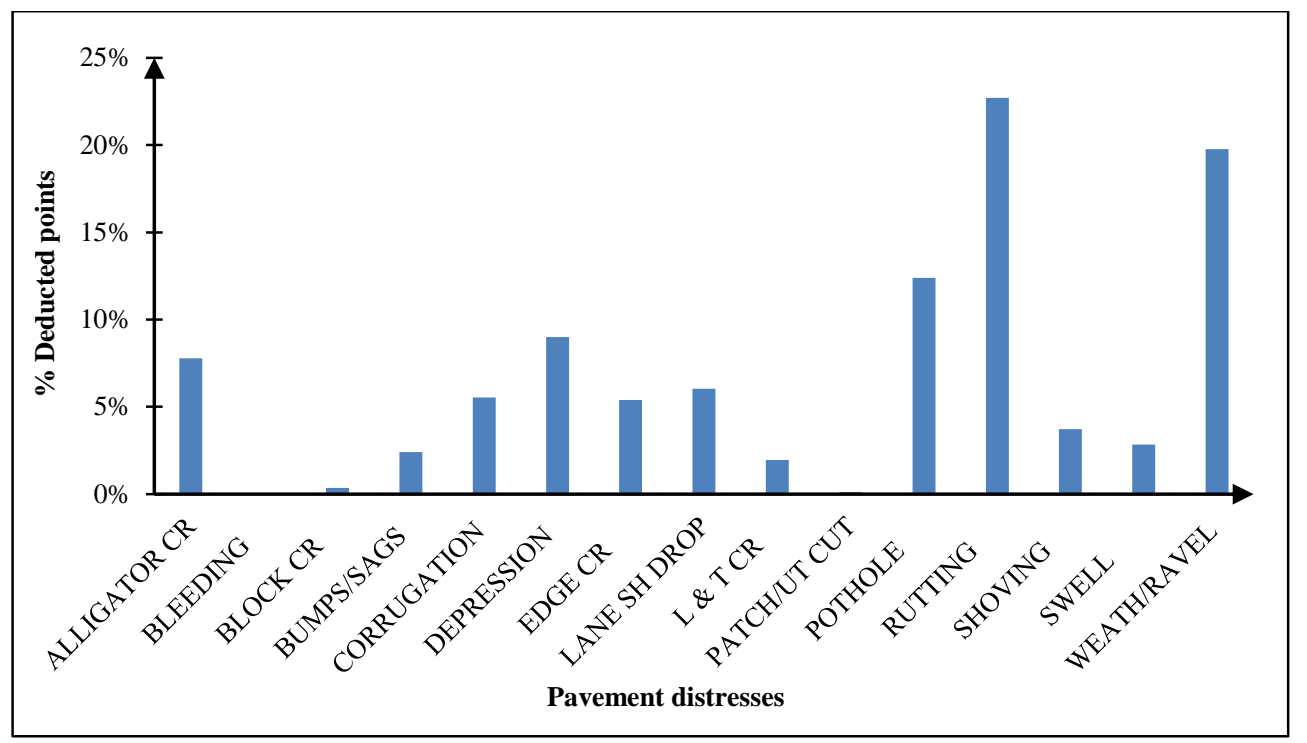

Figure 13. The Pavement Distresses against Deducted Points Percentage of the Sections with Speed Humps on Kafr ElSheikh- Biala Road

\section{c. Kafr El-Sheikh- Baltim Road}

Figure 14 shows the pavement distresses against deducted points percentage for all samples with humps on Kafr ElSheikh- Biala road. The figure shows that the most widely observed distress is Rutting, which was contributed $23 \%$ of the total deducted points before the correction. Also, Raveling was contributed $22 \%$ of the total deducted points before the correction.

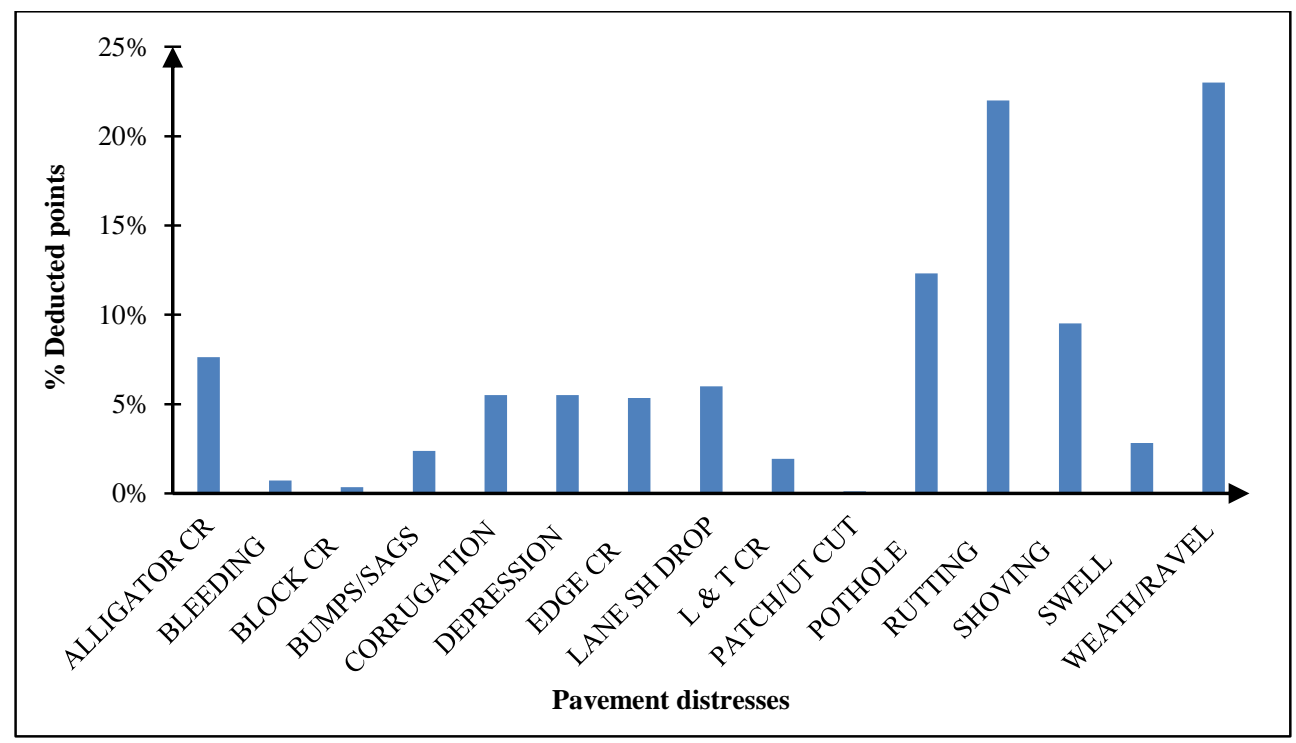

Figure 14. The Pavement Distresses against Deducted Points Percentage of the Sections with Speed Humps on Kafr ElSheikh- Baltim Road

\subsubsection{The Effect of the Presence of Speed Humps}

The average pavement condition of the sections with humps was compared to those with no humps on the same road. This comparison allowed for investigating the effect of speed humps on pavement condition, in isolation of other factors such as traffic, structural capacity, age, construction quality, etc., since all these factors are constant within each studied road. 


\section{a. Kafr El-Sheikh- Sidi Salem Road}

Table 5 indicates the results of t-test (comparing group means) for this comparison. Results can show that Sig. (2tailed) value is lower than 0.05 (95\% confidence), which means that the presence of the speed humps significantly decreases the PCI value of the sample, and that the average reduction in PCI values on the road level due to the presence of speed humps was approximately $17 \%$.

Table 5. The Results of T-Test (Comparing Group Means) for Kafr El-Sheikh- Sidi Salem Road

\begin{tabular}{|c|c|c|c|c|c|c|c|c|}
\hline \multicolumn{9}{|c|}{ Group Statistics } \\
\hline & \multicolumn{2}{|l|}{ Group } & $\mathbf{N}$ & \multicolumn{2}{|c|}{ Mean } & Std. Deviation & \multicolumn{2}{|r|}{ Std. Error Mean } \\
\hline \multirow{2}{*}{$\vec{\nu}$} & No Humps & & 15 & \multicolumn{2}{|c|}{62.33} & 8.94 & \multicolumn{2}{|r|}{2.31} \\
\hline & Humps & & 15 & \multicolumn{2}{|c|}{44.93} & 8.62 & \multicolumn{2}{|r|}{2.22} \\
\hline \multicolumn{9}{|c|}{ Independent Samples Test } \\
\hline & & \multicolumn{7}{|c|}{ t-test for Equality of Means } \\
\hline & & \multirow[t]{2}{*}{$\mathbf{t}$} & \multirow[t]{2}{*}{ df } & \multirow{2}{*}{$\begin{array}{c}\text { Sig. } \\
\text { (2-tailed) }\end{array}$} & \multirow{2}{*}{$\begin{array}{c}\text { Mean } \\
\text { Difference }\end{array}$} & \multirow{2}{*}{$\begin{array}{l}\text { Std. Error } \\
\text { Difference }\end{array}$} & \multicolumn{2}{|c|}{$\begin{array}{l}\text { 95\% Confidence Interval of } \\
\text { the Difference }\end{array}$} \\
\hline & & & & & & & Lower & Upper \\
\hline \multirow{2}{*}{$\overrightarrow{0}$} & $\begin{array}{l}\text { Equal variances } \\
\text { assumed }\end{array}$ & 5.423 & 28 & 0.000 & 17.40 & 3.20 & 10.82 & 23.97 \\
\hline & $\begin{array}{c}\text { Equal variances not } \\
\text { assumed }\end{array}$ & 5.423 & 27.96 & 0.000 & 17.40 & 3.20 & 10.82 & 23.97 \\
\hline
\end{tabular}

\section{b. Kafr El-Sheikh- Biala Road}

Table 6 indicates the results of t-test (comparing group means) for this comparison. Results can show that Sig. (2tailed) value is lower than 0.05 (95\% confidence), which means that the presence of the speed humps significantly decreases the PCI value of the sample, and that the average reduction in PCI values on the road level due to the presence of speed humps was approximately $15 \%$.

Table 6. The Results of T-Test (Comparing Group Means) for Kafr El-Sheikh- Biala Road

\begin{tabular}{|c|c|c|c|c|c|c|c|c|}
\hline \multicolumn{9}{|c|}{ Group Statistics } \\
\hline & \multicolumn{2}{|l|}{ Group } & $\mathbf{N}$ & \multicolumn{2}{|c|}{ Mean } & Std. Deviation & \multicolumn{2}{|c|}{ Std. Error Mear } \\
\hline \multirow{2}{*}{$\bar{Q}$} & No Humps & & 15 & \multicolumn{2}{|c|}{56.33} & 6.74 & \multicolumn{2}{|c|}{1.74} \\
\hline & Humps & & 15 & \multicolumn{2}{|c|}{41.46} & 8.14 & \multicolumn{2}{|c|}{2.1} \\
\hline \multicolumn{9}{|c|}{ Independent Samples Test } \\
\hline & & \multicolumn{7}{|c|}{ t-test for Equality of Means } \\
\hline & & \multirow{2}{*}{$\mathbf{t}$} & \multirow{2}{*}{ df } & \multirow{2}{*}{$\begin{array}{l}\text { Sig. } \\
\text { (2-tailed) }\end{array}$} & \multirow{2}{*}{$\begin{array}{c}\text { Mean } \\
\text { Difference }\end{array}$} & \multirow{2}{*}{$\begin{array}{l}\text { Std. Error } \\
\text { Difference }\end{array}$} & \multicolumn{2}{|c|}{$\begin{array}{l}95 \% \text { Confidence Interval o } \\
\text { the Difference }\end{array}$} \\
\hline & & & & & & & Lower & Upper \\
\hline \multirow{2}{*}{$\bar{\Omega}$} & $\begin{array}{l}\text { Equal variances } \\
\text { assumed }\end{array}$ & 5.44 & 28 & 0.000 & 14.86 & 2.73 & 9.27 & 20.46 \\
\hline & $\begin{array}{c}\text { Equal variances not } \\
\text { assumed }\end{array}$ & 5.44 & 27.05 & 0.000 & 14.86 & 2.73 & 9.26 & 20.47 \\
\hline
\end{tabular}

\section{c. Kafr El-Sheikh- Baltim Road}

Table 7 indicates the results of t-test (comparing group means) for the collected data from Kafr El-Sheikh- Baltim Road. Results can show that Sig. (2-tailed) value is lower than 0.05 (95\% confidence), which means that the presence of the speed humps significantly decreases the PCI value of the sample and that the average reduction in PCI values on the road level due to the presence of speed humps was approximately $22 \%$.

Table 7. The Results of T-Test (Comparing Group Means) for Kafr El-Sheikh- Baltim Road

\begin{tabular}{cccccc}
\hline \multicolumn{5}{c}{ Group Statistics } \\
\hline & Group & N & Mean & Std. Deviation & Std. Error Mean \\
\hline \multirow{2}{*}{} & No Humps & 30 & 71.9333 & 10.16055 & 1.85505 \\
& Humps & 30 & 49.6000 & 9.66900 & 1.76531 \\
\hline
\end{tabular}




\begin{tabular}{|c|c|c|c|c|c|c|c|c|}
\hline \multicolumn{9}{|c|}{ Independent Samples Test } \\
\hline & & \multicolumn{7}{|c|}{ t-test for Equality of Means } \\
\hline & & \multirow[t]{2}{*}{$\mathbf{t}$} & \multirow{2}{*}{ df } & \multirow{2}{*}{$\begin{array}{c}\text { Sig. } \\
\text { (2-tailed) }\end{array}$} & \multirow{2}{*}{$\begin{array}{c}\text { Mean } \\
\text { Difference }\end{array}$} & \multirow{2}{*}{$\begin{array}{l}\text { Std. Error } \\
\text { Difference }\end{array}$} & \multicolumn{2}{|c|}{$\begin{array}{l}\text { 95\% Confidence Interval of } \\
\text { the Difference }\end{array}$} \\
\hline & & & & & & & Lower & Upper \\
\hline \multirow{2}{*}{$\bar{Q}$} & $\begin{array}{l}\text { Equal variances } \\
\text { assumed }\end{array}$ & 8.72 & 58 & 0.000 & 22.33 & 2.56 & 17.20 & 27.45 \\
\hline & $\begin{array}{c}\text { Equal variances not } \\
\text { assumed }\end{array}$ & 8.72 & 57.85 & 0.000 & 22.33 & 2.56 & 17.20 & 27.45 \\
\hline
\end{tabular}

\section{Conclusions}

Based on the results and analyses of this research, the following conclusions are drawn:

- The presence of the speed humps significantly decreases the PCI value of the samples with speed humps and that the average reduction in PCI values on the road level due to the presence of speed humps is approximately $15 \%, 17 \%$ and $22 \%$ for Kafr El-Sheikh- Biala road, Kafr El-Sheikh- Sidi Salem road and Kafr El-SheikhBaltim road, respectively.

- The most frequently observed distresses on the pavement samples with humps considered for the selected roads are Raveling, and Rutting. Where the Rutting is considered as load-related distress while Raveling is a functional distress.

- The most frequently observed distress on the pavement samples without humps considered for the selected roads is Alligator Cracking. Where the Alligator Cracking is considered as load-related distress. As a result, it could be deduced that the standard pavement structure used by RTD is not structurally adequate for the average traffic levels.

- In order to avoid the pavement defects at the locations where the speed humps are installed, it is proposed to study the structural section of the road in the vicinity of the speed hump to resist the braking force and speed reduction effect.

\section{Conflicts of Interest}

The authors declare no conflict of interest.

\section{References}

[1] Shwaly, Sayed A., Mohamed H. Zakaria, and Amal H. Al-Ayaat. "Development of Ideal Hump Geometric Characteristics for Different Vehicle Types 'Case Study' Urban Roads in Kafr El-Sheikh City (Egypt).” Advances in Civil Engineering 2018 (December 19, 2018): 1-12. doi:10.1155/2018/3093594.

[2] Bekheet, Wael. "Short Term Performance and Effect of Speed Humps on Pavement Condition of Alexandria Governorate Roads." Alexandria Engineering Journal 53, no. 4 (December 2014): 855-861. doi:10.1016/j.aej.2014.09.009.

[3] Lav, A. Hakan, Ertugrul Bilgin, and A. Hilmi Lav. "A Fundamental Experimental Approach for Optimal Design of Speed Bumps." Accident Analysis \& Prevention 116 (July 2018): 53-68. doi:10.1016/j.aap.2017.05.022.

[4] Zainuddin, N. I., M. A. Adnan, and J. Md Diah. "Optimization of Speed Hump Geometric Design: Case Study on Residential Streets in Malaysia." Journal of Transportation Engineering 140, no. 3 (March 2014): 05013002. doi:10.1061/(asce)te.19435436.0000611 .

[5] Arbogast, Helen, Melissa Patao, Natalie Demeter, Shelby Bachman, Elizabeth Devietti, Jeffrey S. Upperman, and Rita V. Burke. "The Effectiveness of Installing a Speed Hump in Reducing Motor Vehicle Accidents Involving Pedestrians under the Age of 21." Journal of Transport \& Health 8 (March 2018): 30-34. doi:10.1016/j.jth.2017.11.004.

[6] Gedik, Abdulgazi, Ertugrul Bilgin, Abdullah Hilmi Lav, and Reha Artan. "An Investigation into the Effect of Parabolic Speed Hump Profiles on Ride Comfort and Driving Safety under Variable Vehicle Speeds: A Campus Experience.” Sustainable Cities and Society 45 (February 2019): 413-421. doi:10.1016/j.scs.2018.11.040.

[7] Januševičius, T., and R. Grubliauskas. "The Effect of Speed Bumps and Humps on the Concentrations of CO, NO and NO2 in Ambient Air.” Air Quality, Atmosphere \& Health (April 1, 2019). doi:10.1007/s11869-019-00683-y.

[8] Abdel-Wahed, Talaat Ali, and Ibrahim Hassan Hashim. "Effect of Speed Hump Characteristics on Pavement Condition.” Journal of Traffic and Transportation Engineering (English Edition) 4, no. 1 (February 2017): 103-110. doi:10.1016/j.jtte.2016.09.011.

[9] Taherdoost, Hamed. "How to Design and Create an Effective Survey/Questionnaire; A Step by Step Guide." International Journal of Advance Research in Management 5, no.4 (2018). 
[10] Sharma, S. C., and Y. Leng. "Seasonal traffic counts for a precise estimation of AADT." ITE Journal 64, no.9 (1994).

[11] Shahin, M. Y. "Pavement Management for Airports, Roads, and Parking Lots" (1994). doi:10.1007/978-1-4757-2287-1.

[12] Egyptian Code of Practice for Urban and Rural Road Works. Ministry of Housing, Infrastructure, and Urban Development, Egypt (2008).

[13] Mahmood, M, M Rahman, S Mathavan, and L Nolle. "Pavement Management: Data Centric Rules and Uncertainty Management in Section Classification by a Fuzzy Inference System.” Bituminous Mixtures and Pavements VI (May 21, 2015 ): 533-541. doi:10.1201/b18538-77.

[14] WU, Kan. "Development of PCI-based Pavement Performance Model for Management of Road Infrastructure System.” Arizona State University (MSc 2015).

[15] Hein, David, and Robert Burak. "Development of a pavement condition rating procedure for interlocking concrete pavements." Prepared for Session of Cost-Effective Assessment Rehabilitation of the Condition of Materials for Transportation Association of Canada Fall 2007 meeting, Saskatoon, Saskatchewan, (2007). 